usually made to place a senior and experienced lawyer in charge of the matter so that if legal action becomes necessary, he can continue the case. $\mathrm{He}$ is given as assistants a junior lawyer, a law clerk, an economic expert and such additional assistants as the particular circumstances may require. The unit thus constituted is primarily responsible for supervising the major investigation. It makes periodic reports of its progress to the Assistant Attorney General, but efficient enforcement requires that it carry on the routine investigation under delegated responsibility.

\title{
III. PROCESSES IN THE INVESTIGATION OF COMPLAINTS
}

\section{Charles L. Terreq*}

Broadly defined, investigation in the Antitrust Division of the Department of Justice includes all the inquiry for facts, from the moment the original complaint is received until the case has been dropped, or decided in trial. The economic analysis and study required in the process of selecting cases for investigation, as set forth in the preceding section, is the beginning of the investigation itself. If the decision is to make a further investigation, the effort expands constantly in scope, but the methods and techniques employed continue to be quite similar to those used in the preliminary analysis. However, when this investigation has reached the stage at which a recommendation has been approved that a grand jury action be instituted, there is an appreciable change in the nature of the investigation and the technique involved. Therefore, separate treatment will be given herein to the process of study, analysis and investigation employed for the purpose of recommending the institution of a grand jury proceeding, and to the process of investigation employed for the purpose of producing evidence before a grand jury or petit jury.

The process of investigation is continuous, each successive stage of expanding effort depending upon the nature of the facts accumulated in the previous stages, tempered and qualified by the administrative decisions referred to in the previous section.

\section{Preliminary Study and Investigation}

After a complaint has been reinforced by additional relevant information obtained from the complainant, it may be followed up by a brief field investigation conducted by the Federal Bureau of Investigation, or it may appear to be of such substance as to merit immediate consideration by the Economic Section of the Division. This represents the practical beginning of an antitrust investigation.

At this stage of the investigation the objective, which will remain unchanged until

- A.B., 1928, Ohio State University; M.B.A., 1932, Harvard Business School. On the staff of the Antitrust Division of the United States Department of Justice since 1938 . Prior to 1936 engaged in manufacturing and banking activities; on the staff of the Federal Communications Commission, 1936-1838. 
recommendation is made that a grand jury be called to hear the evidence, is to determine completely and define accurately the competitive pattern in the industry. It may end with a strong indication of antitrust law violation on the part of a certain company or several companies, but its objective continues to be industry-wide in scope. The sources consulted and the methods used reflect the gradually expanding nature of the effort involved.

At the outset an effort is made to learn with the least possible expenditure of time the peculiar characteristics of the industry, the dominant members of the industry, interrelations between members of the industry, connections (financial, commercial or personal) between this industry and other industries, and the recent technical, financial or organization changes within the industry which may have affected the competitive balance. Library materials and Department files furnish the sources for this analysis. The financial manuals (such as Poor's, Moody's, and Standard Statistics) are consulted to learn the products, the number and relative size of competitors, and their respective financial condition and progress. The Commercial and Financial Chronicle, Barron's and the Analyst afford sources for some appreciation of the recent events in the industry which are relevant to the competitive position of the several companies, particularly the larger and dominant members. Reorganizations, mergers, or definite changes in executive control or ownership by dominant members, over a considerable number of years, are reviewed for their bearing upon competition in the industry. For this purpose, in addition to the sources above cited, recourse may be had to newspapers, general and trade periodicals, and their indices.

An essential result of this study is a reasonably accurate understanding of those competitive characteristics of the industry which distinguish it from other industries. Most industries will be found to have a "bottle-neck" in their operation or processes, which may have relatively great influence on the competitive pattern. In some instances the bottleneck may be in patents, resulting from the fact that one or several concerns have a considerable advantage from exclusive access to certain product refinements or manufacturing processes. In other instances the availability or control of raw materials may be a controlling factor. Control over the established available merchandising channels often is the outstanding characteristic; sometimes the investment requirements are such that mere access to unlimited or superior financial resources may be the determinant. Common ownerships or relations which may afford influence over an appreciable fraction of the consuming market may be a less evident but none-the-less effective competitive factor.

In addition to this determination of the competitive pattern inherent in the operation of the industry as a whole, there is the necessity of learning the specific competitive pressures on each of the major or influential concerns within the industry. The natural advantages or disadvantages of each company may result in presenting its executives with particular problems not faced by the management of others in the industry. This understanding sometimes affords a relatively clear explanation for the reactions or alleged violations of particular concerns. A strongly 
financed company with a poor product, facing an emerging competitor with weak financial backing but with a strong new product may resort to measures which would prevent the new product from gaining access to the available distribution channels except at the expenditure of considerable sums of money. A few established but stolid concerns in an industry, facing new price competition by an aggressively managed competitor, may for the first time feel constrained to go beyond mere price leadership practices and resort either to price understandings or to punitive measures through price cutting only in the territory or on the specific product where the new price competitor is obtaining its greatest volume or best profit margin. In any event the competitive pattern of the industry and the particular competitive pressures upon each of the influential members must be determined with accuracy and comprehensiveness, or the subsequent investigation will lack perspective, and run the risk of wasting time and effort in a search for facts in fields which should have been known to be sterile.

A concomitant or subsequent check is made upon the existing files in the Department, not only upon the companies specifically named in the original complaint, but upon all important companies within the same industry. The Department's files often contain a record of activities and history of the industry extending back a quarter of a century or more. When reviewed extensively they afford in themselves a record of the competitive disturbances common to the industry, and yield important conclusions on the usual methods of operation of the dominant members. On occasion this perusal of the files of the Department of Justice is supplemented by references to the files of other Government agencies, such as the Securities and Exchange Commission, the Federal Trade Commission, and the Bureau of Internal Revenue.

During the course of the investigation thus far described, recourse may have been had, or may now be had, to the facilities of the Federal Bureau of Investigation, to answer specific questions of fact. The Bureau is depended upon for acquisition of specific facts, but the antitrust investigator must assume full responsibility for their synthesis, analysis and corroboration. The same list of questions directed to two different sectors of the industry may elicit two completely different reactions. Hence the investigator must be prepared to evaluate the significance of both reactions, largely on the basis of his previous industry analysis.

At this point in the investigation process, if further effort is suggested by the results thus far obtained, it may become necessary for the investigator to conduct a field investigation before recommending that a grand jury be called to consider evidence on probable violation of the antitrust laws. During this field investigation it is the practice of the Department's investigators to interview those persons in the industry who are in a position to check the findings of the previous investigation. These usually are the executive officers of the industry's dominant concerns, with the possible exception of those concerns whose activities are by this time under particular scrutiny. This field study usually is not confined to interviews, but quite generally eventuates in requests to review the files of those concerns from whose correspond- 
ence relevant information can be obtained. The detailed information provided by such correspondence usually is very helpful in the construction of an accurate competitive picture of the industry. For obvious reasons, such requests generally are confined to those concerns whose activities have appeared to be above suspicion. Refusals to allow the Department complete access to files in response to such requests sometimes directs attention to additional subjects for inclusion in the subsequent recommendation for grand jury action.

\section{Investigation in Connection with Grand Jury Action}

After a recommendation has been made, on the basis of the investigation outlined above, that the investigation be dropped or that a grand jury be called to consider specific evidence of antitrust law violation, the objective of the investigation changes in character. Previously the study has been conducted for the purpose of understanding the competitive pattern in the industry, the position of each of the major concerns, and the results of the type of competition actually existing. Now, however, the effort becomes more specific, and the purpose is to determine with finality the existence of violations. No distinction is made between the investigation for presentation of evidence before a grand jury and the acquisition of evidence for presentation in subsequent trial, as it is the practice not to seek an indictment until and unless the evidence collected is of such nature as to indicate that a convincing case can be placed before a jury.

During the presentation of evidence before a grand jury the Department's investigators work with the grand jury, and make use of the powers of subpoena available to grand juries. Evidence is obtained through interviews with prospective grand jury witnesses, and through perusal of documents obtained under subpoena power from files of the members of the industry. Such file information usually is required from all factors in the industry, whether the subjects under subpoena have or have not apparently participated in the activities under review. Those against whom illegal restraints have been practiced are just as likely to have information of evidentiary value in their files as those who are responsible for such restraints.

Subpoenas drawn for the purpose of obtaining relevant material from such files generally are prepared so as to be quite specifically limited by reference both to subject matter contained in the material requested, and by the origin or destination of the correspondence or memoranda thus specified. Despite these close limitations as to the material requested, when applied to companies of even moderate size, they result in placing a considerable responsibility upon the company under subpoena. For that reason the Department frequently offers to conduct a file search in lieu of physical compliance with the subpoena. Under this arrangement, the investigators, as agents of the grand jury, are given complete and unqualified access to the subject company's files, review them for selection of those documents which are included within the scope of the subpoena, and request only those which possess such evidentiary value as to require that they be transmitted to the grand jury for its consideration. The usual result is to require the submission of a comparatively few documents. Indeed, in a large percentage of cases, such a survey of the files 
indicates that no material need be so produced. The adoption of this expedient is accepted almost universally in those instances in which the Department can spare personnel to make such perusal at the offices of the company subpoenaed. An attractive element in such an arrangement is that the company may be relieved of the possibility of contempt proceedings based upon non-compliance with the terms of the subpoena.

There have been instances in which such an offer cannot be made by the Department, due to limitations in personnel. In these cases, as well as in those instances in which the company subpoenaed prefers to accept the full responsibility of compliance therewith, it is necessary to require a strict compliance with all the terms of the subpoena. Accordingly, more than usual attention is given to the accuracy of compliance with those subpoenas, and a check is made upon the proper compliance therewith, by one or more of several means available to the Department. The highly integrated nature of business affairs of today, together with the complete and repetitious record made in the course of usual business correspondence contained in the files of the members of the industry, makes it a relatively easy matter to check the accuracy of compliance with subpoena requests. Original letters written by the subject subpoenaed are contained in, and can be obtained from, the files of other companies. This affords a record of the carbon copies which should be available in the files of the company subpoenaed. Memoranda and related correspondence in the files of other companies leave a broad trail of evidence upon not only the letters and other written evidence in the files of the subject subpoenaed, but also upon the conversations and statements of the officers of companies under subpoena. Correspondence passing between third parties likewise furnishes a considerable source of information upon the correspondence of any specific company subpoenaed. These and other available checking methods are applied in those instances in which it is impossible, for one reason or another, for the Department's staff members to make a direct selection of materials from the files of companies under subpoena.

Witnesses whose testimony is desired either in connection with the grand jury proceedings or in connection with possible later presentation of evidence before a petit jury, are contacted either by the Bureau or by the Division's investigators. It is the policy in investigation during grand jury proceedings immediately to acquire practically all evidence required to present the case before a petit jury, should the grand jury return an indictment. The practice, therefore, is to put into the transcript of hearings before the grand jury, a considerable part of the testimony, both documentary or oral, required to support a strong presentation before a trial jury. It is a prime necessity that such thorough presentation be made since the process of investigation becomes somewhat more complicated once an indictment has been returned, and the industry is clearly advised as to the exact nature of the violations under investigation. When the investigation has been conducted properly, there is no necessity for further extensive investigation after an indictment has been obtained, as evidence sufficient for strong presentation during the subsequent trial already is in the transcript of the grand jury, or in the files of the Department. 